\title{
Highlights for Dental Care as a Hepatitis C Risk Factor: A Review of Literature
}

\author{
Leon D. Averbukh* and George Y. Wu \\ Department of Medicine, Division of Gastroenterology-Hepatology, University of Connecticut Health Center, CT, USA
}

\begin{abstract}
Hepatitis C (HCV) is a viral infection that affects an estimated 71 million people worldwide, with over 1 million new infections yearly. While medical treatments exist, HCV continues to be a significant public health concern. Primary prevention and transmission risk factor identification remain key in helping decrease disease prevalence. While intravenous drug use, healthcare exposure (i.e. blood transfusions and surgical care), and body modification (i.e. tattooing and piercings) are well accepted risk factors for HCV transmission, others remain controversial. Because dental practice is often associated with procedures and bleeding, the possibility of HCV transmission seemed reasonable to investigate. Here, we review the evidence for dental care as a potential risk factor for HCV transmission. We identified a total of 1,180 manuscripts related to HCV and dental care, of which 26 manuscripts were included in the study after exclusionary criteria were applied. As per our review of the available literature, in the developing world, the improper use of sterile technique and lack of provider education likely increases the risk of HCV transmission during dental care. In developed nations, on the other hand, general dental care does not appear to be a significant risk factor for HCV transmission in non-intravenous drug user patients; although, the improper use and reuse of anesthetics during procedures poses a rare potential risk for viral transmission.
\end{abstract}

Citation of this article: Averbukh LD, Wu GY. Highlights for dental care as a hepatitis $C$ risk factor: A review of literature. J Clin Transl Hepatol 2019;7(4):346-351. doi: 10.14218/ JCTH.2019.00023.

\section{Introduction}

Hepatitis C virus (HCV) is a single-stranded RNA virus of the Flaviviridae family that globally affects an estimated 71 million people chronically, with nearly 1.75 million new infections reported in 2015 alone. ${ }^{1}$ With variable infection rates around the world, HCV has the highest prevalence in the eastern Mediterranean, with $2.3 \%$ of the population affected. ${ }^{1}$ The virus is subdivided into at least six major genotypes, with genotypes 1,2 , and 3 being the most common in

Keywords: Hepatitis C; Oral care; Dental care; Risk factors; Hepatitis. Abbreviations: HCV, hepatitis C; IVDU, intravenous drug use.

Received: 28 June 2019; Revised: 22 September 2019; Accepted: 8 October 2019 * Correspondence to: Leon D. Averbukh, Department of Medicine, Division of Gastroenterology-Hepatology, University of Connecticut Health Center, 236 Farmington Ave., Farmington, CT 06030, USA. Tel: +1-347-306-4752, Fax: +1-860679-1025, E-mail: averbukh@uchc.edu
Europe, South America, and North America, genotype 4 found in the Middle East, Egypt, and central Africa, genotype 5 found exclusively in South Africa, and genotype 6 found in Southeast Asia. ${ }^{2}$ In the USA, $70 \%$ of all HCV infections are caused by genotype $1 .^{3}$

$\mathrm{HCV}$, initially known as the non-A, non-B hepatitis, was first discovered in the 1970s in patients that had previously undergone blood transfusions. ${ }^{4}$ However, it was not until the late 1980s that the virus itself was formally identified. Since the advent of interferon as a treatment for HCV in 1991, rapid progress has been made in the production of both genotypespecific and general therapies for HCV infection. Even with rapidly evolving treatment options, HCV remains without a preventative vaccine. Thus, HCV persists as a public health burden and primary prevention is key.

Many studies have explored the risk factors involved in viral transmission, and at present data has correlated significant transmission risk with intravenous drug use (IVDU), healthcare exposure (i.e. blood transfusions and surgical care), body modification (i.e. tattooing and piercings), as well as from infected mothers to their fetuses. ${ }^{5-8}$ Because dental practice is often associated with bleeding, the possibility of HCV transmission seemed reasonable to investigate.

At present, few studies have investigated the overall risk of dental care as a risk factor for HCV transmission. A review by Mahboobi et al. ${ }^{9}$ identified a weak all-time risk of HBV and HCV infection during dental treatment. For this review, we examined literature from around the world describing investigations of dental care as a potential risk factor for HCV transmission.

\section{Methods}

We conducted a complete literature search using Medline/ PubMed, Scopus, and Google Scholar for case-control studies, investigative before and after studies, surveys, and observational studies examining dental care as a risk factor for HCV transmission. Search terms used consisted of: risk factors, $\mathrm{HCV}$, hepatitis $\mathrm{C}$, oral surgery, transmission, infection, dental care, and oral care. Search hits were limited to studies published during or after the year 2000. The year 2000 was selected as a starting point to limit studies to those with dental care practices most similar to present day and to minimize historical confounding variables. Studies that analyzed co-infectivity with other viruses, such as the human immunodeficiency virus, were excluded from analysis. On initial literature search, 1,180 manuscripts were identified and subsequently narrowed to a final count of 34 manuscripts after search term integration. An additional eight manuscripts were removed after exclusionary criteria were applied. All studies were further subdivided into geographic regions of origin. 


\section{Results}

We found $40 \%$ of the USA/European studies, $37.5 \%$ of the Middle Eastern studies, $33.3 \%$ of the African studies, $100 \%$ of the South American studies, and $60 \%$ of the Asian studies to have found clinically significant HCV transmission risk with dental care. In total, 12 of the 26 studies that met the described search criteria found an association between dental care and HCV infection. ${ }^{10-35}$

Five of the studies queried nationwide data (generally those of European or American origin), twelve examined urban populations, seven examined rural populations, and two investigated a mixed urban/rural population. ${ }^{9-34}$ Sixteen of the studies used adult populations in the sample pool (two of which examined strictly adult pregnant women, one queried only adults over the age of 60 , and one study looked exclusively at adult healthcare workers), six used a mixed pool of adults and children, and four investigated only children. ${ }^{9-34}$ Eighteen of the 26 studies did not define "dental care", and one clarified that all dental care was provided by uncertified providers (Table 1). ${ }^{12,14-19,21,23-28,31,33-35}$

\section{Discussion}

The results of the reviewed studies were conflicting. Close to half of the studies showed dental care as a significant risk factor for HCV transmission, while the rest of the studies showed no significant association. Furthermore, no world region proved to be uniform in study findings (Table 1$){ }^{10-35}$ Findings and conclusions varied even within the same countries. For instance, in Pakistan, three of seven studies found a significant correlation between dental care and HCV transmission; in Egypt, one of five and in China, one of two. ${ }^{16-24,29-33}$ The studies examined do not appear to suffer from a lack of power as sample sizes were relatively large, involving hundreds, if not thousands of respondents. Limitations of study design and the presence of confounding variables highlights how these studies may have resulted in inconsistent data.

\section{Study limitations}

As dental care was not the only variable examined as a potential risk factor for HCV transmission in all reviewed studies, dental care did not receive a high level of detail or subcategorization and was rarely well-defined. Most studies asked participants whether they had any kind of dental care over the span of their respective lifetimes. ${ }^{12,16,31}$ Some studies did qualify the question of previous dental care with specific procedures that defined "dental care", but these were of a broad range of invasiveness, including tooth fillings, filings, extractions, and oral surgeries. ${ }^{22,29,32}$ As participants were not asked to specify the type of dental work they had done, it opened the possibility of data skew given that the risk of HCV transmission is different in cases involving blood exposure, such as during root canal placement versus tooth filings. Additionally, most articles did not define anesthesia use in their definition of dental care, a potential confounding variable as the use of syringes and anesthetic solutions may increase HCV transmission risk.

Other shortcomings of the evaluated studies were the methods for data collection. For instance, Medhat et al. ${ }^{30}$ went door to door, checking blood samples from local citizenry in Pakistan for HCV antibodies, while simultaneously asking the volunteers questions regarding potential HCV exposure risk factors. This method of data collection has a high risk for social desirability bias, a subcategory of response bias where survey respondents answer questions in a manner that they believe will be viewed favorably by others. Given the cultural taboos of topics such as intravenous drug use (IVDU) and sexual history in many parts of the world, Medhat et al.'s ${ }^{30}$ data has a high risk for respondent bias skew. The investigators themselves admit that given the cultural taboos of Pakistan, they avoided directly asking participants whether they practiced IVDU. As IVDU is a known risk factor for HCV transmission, the potential for confounding variable presence in the analyzed data is high. To offset the potential confounding effect of not knowing participant IVDU history, Medhat et al. ${ }^{30}$ questioned use of shared syringes, a common practice in the region. Unfortunately, this does not exclude IVDU as a confounding variable, as at present there are no data showing whether the sharing of syringes within a family nucleus is a risk factor for HCV transmission and/or if it correlates to transmission risks associated with IVDU.

Unfortunately, the lack of identification and exclusion of IVDU was a common shortcoming across studies, whether because of omission of participant questioning or non-differentiation of IVDU from the population pool. Only three of the studies either excluded participants who admitted to IVDU or performed repeat statistical analyses accounting for IVDU as a known variable. ${ }^{10,23,24}$ Dental care was found not be a significant risk factor for HCV transmission in two of the three studies, when IVDU was excluded. ${ }^{10,23}$ Murphy et al. ${ }^{10}$ demonstrated the confounding nature of IVDU, as when IV drug users were excluded from the study population there was no significant difference between dental care and HCV transmission, while the opposite was true when the same population was included. While it is unclear why IVDU is a confounding variable for HCV transmission in dental care, it is possible that because data is obtained by check box questionnaires, individuals who practice IVDU require more dental care on average than their non-IVDU counterparts due to drug side effects and lifestyle.

Another type of bias which may have limited the findings of the presented studies is Berkson bias. Berkson bias is a type of selection bias generally found when study samples are taken from a subpopulation rather than the general population. Nationwide data for sample analysis was used in only five of the twenty-six studies (Table 1). ${ }^{10-12,14,27}$ Instead, most studies either investigated specific environments, i.e. urban or rural regions, or certain demographics, such as pregnant women, healthcare workers, or children. In addition to increasing the risk of Berkson bias with the aforementioned subpopulations, the inclusion of children also increased the probability of social desirability bias. In Barakat et al., ${ }^{33}$ parents were asked to answer questionnaires about their children's potential risk factors for HCV infection. Based on the child age groups being studied, parents may have either refrained from being entirely truthful so as not paint themselves in a bad light given cultural taboos or may have answered in a manner they thought was culturally appropriate, even if they were not completely aware of all of their children's exposures.

\section{Age as a clue}

An interesting finding noted in two studies ${ }^{28,29}$ was the significance of age in determining whether dental care was a risk factor for HCV transmission. Habib et al. ${ }^{29}$ noted that with adjustment for age, there was no increased risk for HCV transmission in dental care, while the opposite was true when no 
Averbukh L.D. et al: Dental care as an HCV risk factor

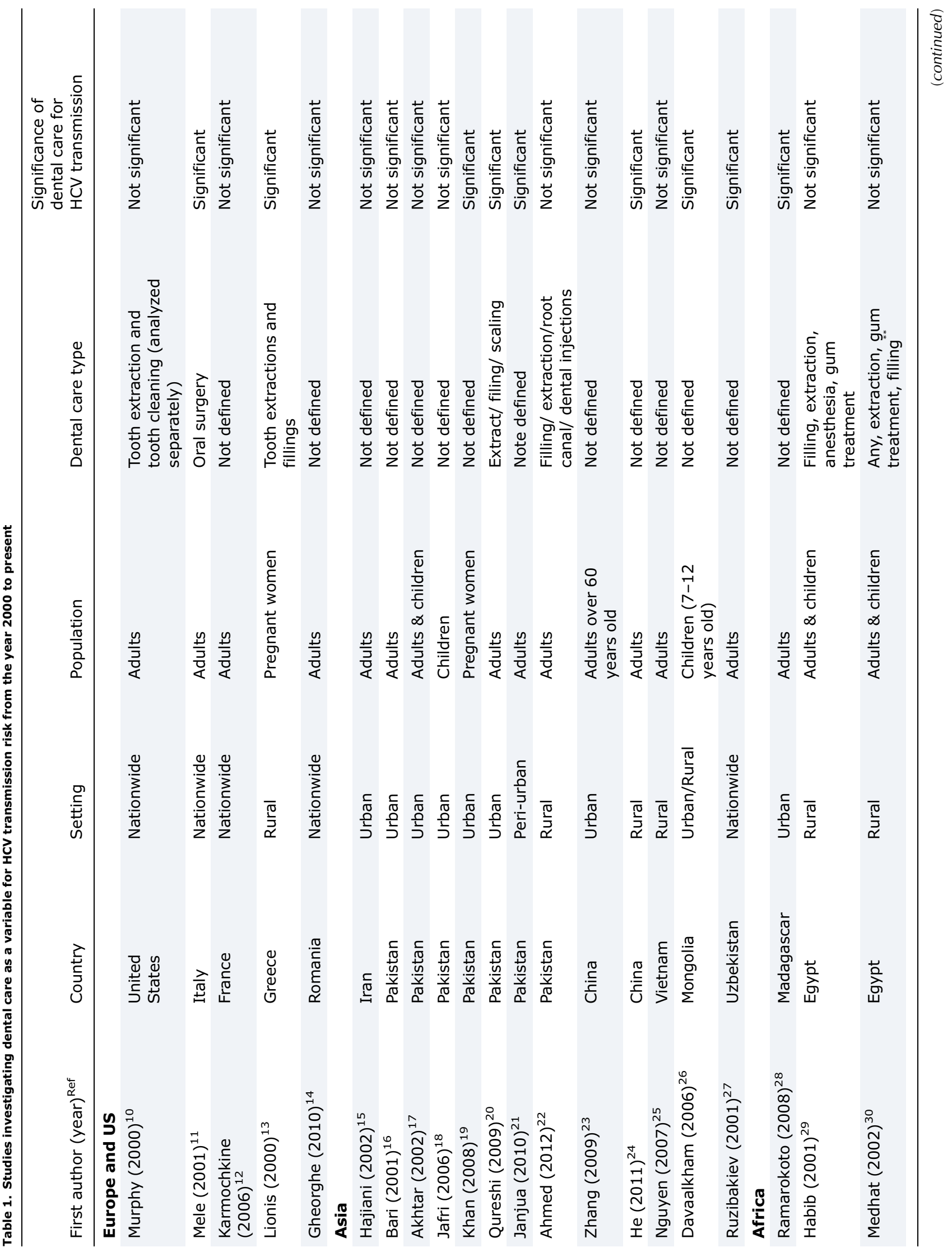


such adjustment was made. Ramarokoto et al. ${ }^{28}$ found that the percentage of HCV seroprevalent individuals with a history of dental care, when categorized by age groups (0-24, 25-44, 45-64, and those over $>64$ years), varied, with those aged between 45 and 64 having the highest seroprevalence.

This finding may be explained by the quality of sterile technique employed or available to the healthcare providers performing the dental procedures. Poor sterilization technique and unsafe injections, factors that would put patients at a higher potential risk of HCV transmission during dental work, may have improved over time to the present, whether secondary to provider education and/or tool accessibility. As to why Ramarokoto et al. ${ }^{28}$ found peak HCV seroprevalence in the 45-64 age group with subsequent decrease, it may be due to survivorship bias, as those that were HCV-infected were less likely to survive to more advanced age.

\section{The risks involved}

In developing countries, the risks associated with HCV transmission during dental care are likely related to improper sterile technique as well as the use of poorly trained or legally practicing but uncertified practitioners. ${ }^{34}$ Studies in the West have generally concluded that dental care is not a risk factor for HCV transmission (Table 1). ${ }^{10,12,14}$ However, the use of anesthesia during dental care, a practice more prevalent in developed nations, remains an important, though not well identified, potential source for HCV transmission. In the USA state of Oklahoma, in 2013, a vial of propofol, initially used during a multitooth extraction from an HCV-seropositive patient was subsequently reused for a patient undergoing a similar procedure. ${ }^{36}$ Unlike general data currently available which identifies statistical association between HCV and transmission risk factors, the Oklahoma case represents proven HCV transmission, and is to date the only such example in the USA.

While the re-use of anesthetic may increase the risk of HCV exposure, the type of anesthetic used may also contribute. Propofol, an injected anesthetic medication used for procedural sedation is lipid rich in content, a property that is beneficial for prolonged HCV particle survival. One study showed high viral particle load in propofol emulsion after 35 days, a duration over which viral particles became undetectable even in optimal cell medium. ${ }^{37}$

While studies investigating $\mathrm{HCV}$ transmission between physicians and patients are limited, it remains an important complicating factor in medical care. Exposure-prone procedures, such as surgery, have shown an association between HCV transmission from seropositive surgical providers to their patients. Studies have found the risk of patient acquisition of $\mathrm{HCV}$ during an operation performed by an infected surgeon to be between 0 and $3.7 \%$, a risk similar to that of acquiring $\mathrm{HCV}$ after a blood transfusion. ${ }^{38-40}$ One retrospective study investigating cardiac surgeons demonstrated a surgeon-to-patient $\mathrm{HCV}$ transmission rate of as high as $6 \%$ during open heart surgery. ${ }^{41}$ The risks of HCV transmission from dental care providers to their patients has not been well studied, and at present no data exists on dentist to patient HCV transmission rates.

Unlike provider-to-patient HCV transmission, the rate of patient-to-surgeon HCV transmission appears to be significantly lower. In a British study investigating surgical interventions and $\mathrm{HCV}$ transmission, rates of $\mathrm{HCV}$ infection amongst surgeons ranged between $0.035 \%$ and $1.12 \%$ over the span of a 35 -year professional career. ${ }^{42}$ The data 
on transmission of $\mathrm{HCV}$ from patients to dentist remains limited. Examining USA data from between the years of 2000 and 2005, the prevalence of HCV antibodies among the general USA population ranged between $1.3 \%$ and $1.6 \%$, while being only $0.47 \%$ amongst dentists, signifying a low occupational risk of $\mathrm{HCV}$ infection amongst USA dentists. ${ }^{43}$

While HCV exposure during cardiac surgery is significantly greater than during dental care, the identification of viral particles in human blood and saliva reported in cases of HCV transmission following splashes of infected blood on broken skin, toothbrush sharing, and viral infectivity makes dental care an important issue. Identification and reduction of potential $\mathrm{HCV}$ transmission risk factors during regular and interventional care remains crucial for both patients and providers. ${ }^{44-47}$

\section{Conclusions}

At present, dental care does pose a risk for HCV transmission, although the extents vary worldwide. In the developing world, the improper use of sterile technique and lack of provider education likely increase the risk of HCV transmission secondary to dental care. In developed nations, general dental care does not appear to be a significant risk factor for HCV transmission when IVDU is an excluded variable. However, anesthesia, more commonly used in developed nations, appears to be a potential risk for viral transmission and should be closely monitored. Unfortunately, current studies on dental HCV transmission contain limitations, including methods of data procurement, lack of IVDU exclusion, Berkson bias, and social desirability bias, which make their findings more difficult to interpret accurately. In the future, studies should focus on large, nationwide samples in which participants with known risk factors for HCV transmission should be excluded. Questionnaires regarding risk factors should be done using methods that best preserve participant anonymity to reduce the risk of social desirability bias. While treatment options for HCV continue to evolve and improve, primary prevention remains paramount for disease eradication.

Standard precautions for dental care remain key in reducing the risk of HCV transmission to patients and providers alike. These precautions include hand hygiene, proper use of protective equipment, such as masks and gloves, proper sharps' handling and injection practices, environmental cleaning, proper use of reusable and single-use medical equipment and drugs, and respiratory hygiene. ${ }^{48}$ Special care should be taken when treating high-risk populations, such as prison inmates and those with human immunodeficiency virus, as these populations have higher rates of HCV infection.

\section{Acknowledgments}

The support of the Herman Lopata Chair for Hepatitis Research is gratefully acknowledged.

\section{Conflict of interest}

The authors have no conflict of interests related to this publication.

\section{Author contributions}

Writing the manuscript (LDA), developing the idea for the article and critically revising it (GYW).

\section{References}

[1] World Health Organization. Hepatitis C. Available from: https://www.who. int/news-room/fact-sheets/detail/hepatitis-c, Accessed 9 July 2019.

[2] Nainan OV, Alter MJ, Kruszon-Moran D, Gao FX, Xia G, McQuillan G, et al. Hepatitis $C$ virus genotypes and viral concentrations in participants of a general population survey in the United States. Gastroenterology 2006; 131:478-484. doi: 10.1053/j.gastro.2006.06.007.

[3] Nguyen $\mathrm{MH}$, Keeffe EB. Prevalence and treatment of hepatitis $\mathrm{C}$ virus genotypes 4, 5, and 6. Clin Gastroenterol Hepatol 2005;3:S97-S101. doi: 10. 1016/S1542-3565(05)00711-1.

[4] Alter H. Discovery of non-A, non-B hepatitis and identification of its etiology Am J Med 1999;107:16S-20S. doi: 10.1016/s0002-9343(99)00375-7.

[5] Xia X, Luo J, Bai J, Yu R. Epidemiology of hepatitis C virus infection among injection drug users in China: systematic review and meta-analysis. Public Health 2008;122:990-1003. doi: 10.1016/j.puhe.2008.01.014.

[6] Wilkins T, Malcolm JK, Raina D, Schade RR. Hepatitis C: diagnosis and treatment. Am Fam Physician 2010;81:1351-1357.

[7] Jafari S, Copes R, Baharlou S, Etminan M, Buxton J. Tattooing and the risk of transmission of hepatitis $\mathrm{C}$ : a systematic review and meta-analysis. Int J Infect Dis 2010;14:e928-e940. doi: 10.1016/j.jid.2010.03.019.

[8] Alter MJ. Epidemiology of hepatitis C virus infection. World J Gastroenterol 2007;13:2436-2441. doi: 10.3748/wjg.v13.i17.2436.

[9] Mahboobi N, Porter SR, Karayiannis $P$, Alavian SM. Dental treatment as a risk factor for hepatitis $B$ and $C$ viral infection. A review of the recent literature. J Gastrointestin Liver Dis 2013;22:79-86.

[10] Murphy EL, Bryzman SM, Glynn SA, Ameti DI, Thomson RA, Williams AE, et al. Risk factors for hepatitis $C$ virus infection in United States blood donors. NHLBI Retrovirus Epidemiology Donor Study (REDS) Hepatology 2000;31:756-762. doi: 10.1002/hep.510310329.

[11] Mele A, Spada E, Sagliocca L, Ragni P, Tosti ME, Gallo G, et al. Risk of parenterally transmitted hepatitis following exposure to surgery or other invasive procedures: results from the hepatitis surveillance system in Italy. J Hepatol 2001;35:284-289. doi: 10.1016/s0168-8278(01)00111-8.

[12] Karmochkine M, Carrat F, Dos Santos O, Cacoub P, Raguin G. A case-control study of risk factors for hepatitis $C$ infection in patients with unexplained routes of infection. J Viral Hepat 2006;13:775-782. doi: 10.1111/j.13652893.2006.00742.x.

[13] Lionis C, Vlachonikolis IG, Skliros S, Symeonidis A, Merkouris BP, Kouroumalis $E$. Do undefined sources of hepatitis $C$ transmission exist? The Greek study in General Practice. J Viral Hepat 2000;7:218-224. doi: 10.1046/j. 1365-2893.2000.00217.x.

[14] Gheorghe L, Csiki IE, Iacob S, Gheorghe C, Smira G, Regep L. The prevalence and risk factors of hepatitis $C$ virus infection in adult population in Romania: a nationwide survey 2006-2008. J Gastrointestin Liver Dis 2010;19:373-379.

[15] Hajiani E, Masjedizadeh R, Hashemi J, Azmi M, Rajabi T. Hepatis C virus transmission and its risk factors within families of patients infected with hepatitis C virus in southern Iran: Khuzestan. World J Gastroenterol 2006;12: 7025-7028. doi: 10.3748/wjg.v12.i43.7025.

[16] Bari A, Akhtar S, Rahbar MH, Luby SP. Risk factors for hepatitis C virus infection in male adults in Rawalpindi-Islamabad, Pakistan. Trop Med Int Health 2001;6:732-738. doi: 10.1046/j.1365-3156.2001.00779.x.

[17] Akhtar S, Moatter T, Azam SI, Rahbar MH, Adil S. Prevalence and risk factors for intrafamilial transmission of hepatitis $\mathrm{C}$ virus in Karachi, Pakistan. J Viral Hepat 2002;9:309-314. doi: 10.1046/j.1365-2893.2002.00350.x.

[18] Jafri W, Jafri N, Yakoob J, Islam M, Tirmizi SF, Jafar T, et al. Hepatitis B and C: prevalence and risk factors associated with seropositivity among children in Karachi, Pakistan. BMC Infect Dis 2006;6:101. doi: 10.1186/1471-2334-6-101.

[19] Khan UR, Janjua NZ, Akhtar S, Hatcher J. Case-control study of risk factors associated with hepatitis $\mathrm{C}$ virus infection among pregnant women in hospitals of Karachi-Pakistan. Trop Med Int Health 2008;13:754-761. doi: 10. 1111/j.1365-3156.2008.02075.x.

[20] Qureshi H, Arif A, Riaz K, Alam SE, Ahmed W, Mujeeb SA. Determination of risk factors for hepatitis $B$ and $C$ in male patients suffering from chronic hepatitis. BMC Res Notes 2009;2:212. doi: 10.1186/1756-0500-2-212.

[21] Janjua NZ, Hamza HB, Islam M, Tirmizi SF, Siddiqui A, Jafri W, et al. Health care risk factors among women and personal behaviours among men explain the high prevalence of hepatitis $\mathrm{C}$ virus infection in Karachi, Pakistan. J Viral Hepat 2010;17:317-326. doi: 10.1111/j.1365-2893.2009.01230.x.

[22] Ahmed F, Irving WL, Anwar M, Myles P, Neal KR. Prevalence and risk factors for hepatitis $C$ virus infection in Kech District, Balochistan, Pakistan: most infections remain unexplained. A cross-sectional study. Epidemiol Infect 2012;140:716-723. doi: 10.1017/S0950268811001087.

[23] Zhang M, Fan J, Li H, Cui J, Qiao Y, Sung J, et al. Alternative risk factors of HCV infection in a rural community in China. Epidemiol Infect 2010;138: 1032-1035. doi: 10.1017/S0950268809991269.

[24] He Y, Zhang J, Zhong L, Chen X, Liu HM, Wan LK, et al. Prevalence of and risk factors for hepatitis $C$ virus infection among blood donors in Chengdu, China. J Med Virol 2011;83:616-621. doi: 10.1002/jmv.22010. 
[25] Nguyen VT, McLaws ML, Dore GJ. Prevalence and risk factors for hepatitis $C$ infection in rural north Vietnam. Hepatol Int 2007;1:387-393. doi: 10 . 1007/s12072-007-9008-3.

[26] Davaalkham D, Ojima T, Nymadawa $P$, Uehara R, Watanabe M, Oki I, et al. Prevalence and risk factors for hepatitis $C$ virus infection in Mongolian children: Findings from a nationwide survey. J Med Virol 2006;78:466-472. doi: 10.1002/jmv.20563.

[27] Ruzibakiev R, Kato H, Ueda R, Yuldasheva N, Hegay T, Avazova D, et al. Risk factors and seroprevalence of hepatitis $B$ virus, hepatitis $C$ virus, and human immunodeficiency virus infection in uzbekistan. Intervirology $2001 ; 44: 327-$ 332. doi: 10.1159/000050066.

[28] Ramarokoto CE, Rakotomanana F, Ratsitorahina M, Raharimanga V, Razafindratsimandresy R, Randremanana R, et al. Seroprevalence of hepatitis $C$ and associated risk factors in urban areas of Antananarivo, Madagascar. BMC Infect Dis 2008;8:25. doi: 10.1186/1471-2334-8-25.

[29] Habib M, Mohamed MK, Abdel-Aziz F, Magder LS, Abdel-Hamid M, Gamil F, et al. Hepatitis $C$ virus infection in a community in the Nile Delta: risk factors for seropositivity. Hepatology 2001;33:248-253. doi: 10.1053/jhep.2001. 20797.

[30] Medhat A, Shehata M, Magder LS, Mikhail N, Abdel-Baki L, Nafeh M, et al. Hepatitis $\mathrm{c}$ in a community in Upper Egypt: risk factors for infection. Am J Trop Med Hyg 2002;66:633-638. doi: 10.4269/ajtmh.2002.66.633.

[31] El-Raziky MS, El-Hawary M, Esmat G, Abouzied AM, El-Koofy N, Mohsen N, et al. Prevalence and risk factors of asymptomatic hepatitis $C$ virus infection in Egyptian children. World J Gastroenterol 2007;13:1828-1832. doi: 10. 3748/wjg.v13.i12.1828.

[32] Mostafa A, Taylor SM, el-Daly M, el-Hoseiny M, Bakr I, Arafa N, et al. Is the hepatitis $C$ virus epidemic over in Egypt? Incidence and risk factors of new hepatitis C virus infections. Liver Int 2010;30:560-566. doi: 10.1111/j. 1478-3231.2009.02204.x

[33] Barakat SH, El-Bashir N. Hepatitis C virus infection among healthy Egyptian children: prevalence and risk factors. J Viral Hepat 2011;18:779-784. doi: 10.1111/j.1365-2893.2010.01381.x.

[34] Paraná R, Paiva T, Leite MR, Oliveira FN, Kali N, Lobato C, et al. Infection with hepatitis $\mathrm{C}$ virus among health care workers in the Brazilian Western Amazon region (Rio Branco, State of Acre). Am J Trop Med Hyg 2007;76:165-169. doi: 10.4269/ajtmh.2007.76.165.

[35] Sanchez JL, Sjogren MH, Callahan JD, Watts DM, Lucas C, Abdel-Hamid M, et al. Hepatitis $\mathrm{C}$ in Peru: risk factors for infection, potential iatrogenic transmission, and genotype distribution. Am J Trop Med Hyg 2000;63:242-248. doi: 10.4269/ajtmh.2000.63.242.

[36] Bradley KK. Dental healthcare-associated transmission of hepatitis C: Final report of public health investigation and response, 2013. Available from: https://www.ok.gov/health2/documents/Dental\%20Healthcare_ Final\%20Report_2_17_15.pdf.
[37] Steinmann E, Ciesek S, Friesland M, Erichsen TJ, Pietschmann T. Prolonged survival of hepatitis $C$ virus in the anesthetic propofol. Clin Infect Dis 2011; 53:963-964. doi: 10.1093/cid/cir530.

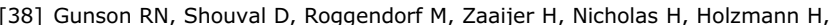
et al. Hepatitis B virus (HBV) and hepatitis C virus ( $\mathrm{HCV}$ ) infections in health care workers (HCWs): guidelines for prevention of transmission of HBV and HCV from HCW to patients. J Clin Virol 2003;27:213-230. doi: 10. 1016/S1386-6532(03)00087-8.

[39] Olsen K, Dahl PE, Paulssen E], Husebekk A, Widell A, Busund R. Increased risk of transmission of hepatitis $C$ in open heart surgery compared with vascular and pulmonary surgery. Ann Thorac Surg 2010;90:1425-1431. doi: 10.1016/j.athoracsur.2010.06.053.

[40] Ross RS, Viazov S, Roggendorf M. Risk of hepatitis C transmission from infected medical staff to patients: model-based calculations for surgical settings. Arch Intern Med 2000;160:2313-2316. doi: 10.1001/archinte.160. 15.2313.

[41] Puro V, De Carli G, Scognamiglio P, Porcasi R, Ippolito G. Risk of HIV and other blood-borne infections in the cardiac setting: patient-to-provider and provider-to-patient transmission. Ann N Y Acad Sci 2001;946:291-309. doi: 10.1111/j.1749-6632.2001.tb03918.x.

[42] Thorburn D, Roy K, Cameron SO, Johnston J, Hutchinson S, McCruden EA, et al. Risk of hepatitis $C$ virus transmission from patients to surgeons: model based on an unlinked anonymous study of hepatitis $C$ virus prevalence in hospital patients in Glasgow. Gut 2003;52:1333-1338. doi: 10.1136/gut. 52.9.1333.

[43] Cleveland JL, Gray SK, Harte JA, Robison VA, Moorman AC, Gooch BF. Transmission of blood-borne pathogens in US dental health care settings: 2016 update. J Am Dent Assoc 2016;147:729-738. doi: 10.1016/j.adaj.2016.03. 020.

[44] Dusheiko GM, Smith M, Scheuer PJ. Hepatitis C virus transmitted by human bite. Lancet 1990;336:503-504. doi: 10.1016/0140-6736(90)92049-n.

[45] Toda T, Mitsui T, Tsukamoto Y, Ebara T, Hirose A, Masuko K, et al. Molecular analysis of transmission of hepatitis $C$ virus in a nurse who acquired acute hepatitis C after caring for a viremic patient with epistaxis. J Med Virol 2009; 81:1363-1370. doi: 10.1002/jmv.21537.

[46] Lock G, Dirscherl M, Obermeier F, Gelbmann CM, Hellerbrand C, Knöll A, et al. Hepatitis C - contamination of toothbrushes: myth or reality? J Viral Hepat 2006;13:571-573. doi: 10.1111/j.1365-2893.2006.00735.x

[47] Recommendations for prevention and control of hepatitis C. virus (HCV) infection and HCV-related chronic disease. Centers for Disease Control and Prevention. MMWR Recomm Rep 1998;47:1-39. doi: 10.1037/e547602006001.

[48] Klevens RM, Moorman AC. Hepatitis C virus: an overview for dental health care providers. J Am Dent Assoc 2013;144:1340-1347. doi: 10.14219/jada. archive.2013.0069. 